\title{
Ativação de Mudanças na Formação Superior em Saúde: Dificuldades e Estratégias
}

\section{Activation of Changes in Higher Education in the Health Professions: Difficulties and Strategies}

\author{
Alberto Durán González ${ }^{I}$ \\ Márcio José de AlmeidaI
}

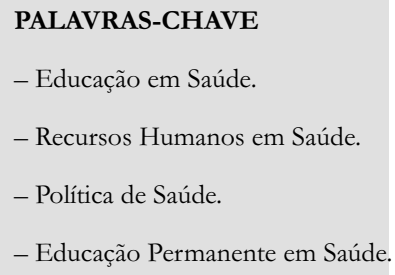

\section{KEY-WORDS}

- Health Education.

- Health Manpower.

- Health Policy.

- Continuing Education in Health.

Recebido em: 04/05/2009

Reencaminhado em: 29/07/2009

Aprovado em: 11/09/2009

REVISTA BRASILEIRA DE EDUCAÇ̃̃o MÉDICA

\footnotetext{
* Artigo baseado em dissertação do curso de Mestrado em Saúde Coletiva da Universidade Estadual de Londrina.

${ }^{I}$ Universidade Estadual de Londrina, Londrina, PR, Brasil.
}

\begin{abstract}
The graduate course on Activation of Change in Higher Education for Health Professionals, launched in 2005, triggered numerous processes of change. However, few activated changes are shared with the scientific community. The current article analyzes difficulties and strategies experienced by alumni of the activation course in Paraná State, Brazil, during the implementation of changes in their local and regional settings. The study adopted a qualitative research methodology with thematic analysis as proposed by Bardin. The sources were secondary data from course monographs and primary data from semi-structured interviews with the monograph authors, which were characterized as action plans. Of the 57 Parana alumni, 25 sent their monographs and 21 were interviewed. The analysis revealed structural, methodological, administrative, financial, and mainly human difficulties. Informative, motivational, and persuasive strategies proved efficient for overcoming various barriers. Since these difficulties and strategies were unveiled, they can be considered in the organization of future plans for change, thereby increasing the odds of the proposal's success.
\end{abstract}

ABSTRACT 


\section{INTRODUÇÃO}

Com a criação do Departamento de Gestão da Educação na Saúde (DEGES), vinculado à Secretaria de Gestão do Trabalho e da Educação na Saúde (SGTES), o Ministério da Saúde (MS) buscou assumir seu papel constitucional na ordenação da formação dos novos profissionais de saúde e na educação permanente dos trabalhadores já inseridos no Sistema Único de Saúde (SUS) ${ }^{1}$.

O MS e o Ministério da Educação (MEC) lançaram, em 2004, o AprenderSUS: o SUS e os cursos de graduação da área da saúde. Esta política constituía um conjunto de estratégias que visava oportunizar e fortalecer a interação entre instituições de ensino superior e o sistema de saúde por meio da implementação das diretrizes curriculares e da adoção da integralidade como eixo norteador dos processos de formação ${ }^{1,2}$.

Com o objetivo de difundir as experiências acumuladas na área de mudança na formação em saúde, o DEGES/SGTES, juntamente com a Escola Nacional de Saúde Pública Sérgio Arouca (ENSP/Fiocruz) e a Rede Unida, desenvolveu, como uma das estratégias do AprenderSUS, o Curso de Especialização em Ativação de Processo de Mudança na Formação Superior de Profissionais de Saúde ${ }^{2,3}$.

Esta estratégia procura avançar nas adequações da formação dos novos profissionais de saúde ${ }^{4,5}$ norteadas pelo princípio da integralidade das ações em saúde ${ }^{6,7}$ - mudanças insistentemente cobradas na literatura e, em especial, pelos usuários do SUS. Especialistas e usuários cobram profissionais capazes de conduzir autonomamente seu processo de aprendizagem ao longo da vida profissional, de exercer proatividade nas mudanças necessárias, com senso crítico, decisão, visão humanística e ética ${ }^{8-10}$.

A mudança na formação superior dos novos profissionais de saúde é necessária, valorizada e estimulada, mas por que é tão difícil mudar? Quais são as estratégias usadas na tentativa de implantar mudanças locorregionais? Este artigo objetiva analisar as dificuldades encontradas e as estratégias lançadas por egressos paranaenses do curso de ativação durante a implantação de processos de mudança em seus cenários locorregionais.

\section{METODOLOGIA}

Este artigo faz parte de um estudo mais amplo cujo objetivo foi refletir sobre o movimento pró-mudança na formação na área da saúde a partir das experiências dos egressos do curso de ativação residentes no Paraná.

Os participantes do curso de especialização foram orientados pelos organizadores do curso a desenvolverem trabalhos de conclusão de curso (TCCs) que contribuíssem para a implantação de um processo de mudança em seus cenários.
A coleta dos dados se deu em duas fases. Os 57 concluintes residentes no Paraná estavam distribuídos em serviços de saúde e instituições de ensino superior públicas e privadas de oito cidades. Na primeira fase, encaminhou-se a todos, por e-mail, uma rápida apresentação do pesquisador e da pesquisa, o termo de consentimento livre esclarecido e o pedido para que enviassem o TCC referente ao curso. Após três tentativas de contato por e-mail e três por telefone, espaçadas nos meses de março e abril, deu-se por finalizado o período de coleta dos TCCs.

Os TCCs selecionados para a segunda fase da coleta de dados foram os que propunham mudanças por meio de ações. Foram separados dos TCCs que relataram experiências anteriores à participação no curso, por se imaginar que estes se encontravam num momento de avaliação e monitoramento; e dos TCCs que se restringiram à reflexão, mas não chegaram a traçar ações, pois estes se encontravam no momento de insatisfação e análise dos cenários.

Dos 57 egressos, 25 enviaram seus TCCs, sendo que 21 TCCs se caracterizaram como planos de ação, e suas autoras, todas do sexo feminino, foram entrevistadas.

As 21 egressas estavam dispersas em seis cidades e atuavam em serviços de saúde, universidades públicas e privadas e/ou faculdades privadas. Os planos de ação foram planejados para diferentes cenários, como: salas de aula, grupos de estudos, oficina multiprofissional de reflexão docente, unidades de estágio hospitalar, clínica da rede de serviços de saúde, polo regional de educação permanente em saúde, módulos acadêmicos multidisciplinares e o curso de graduação como um todo.

As entrevistas semiestruturadas foram realizadas nos meses de maio e junho de 2007 nas cidades de residência das entrevistadas. Antes das entrevistas, as participantes foram relembradas sobre os objetivos da pesquisa, a importância de seus depoimentos e a justificativa da utilização do gravador. Todas concordaram e assinaram o termo de consentimento.

O roteiro da entrevista tinha questões que abordavam: 1) a participação no curso de especialização; 2) a integração entre as competências necessárias à formação do ativador; 3) as facilidades e dificuldades encontradas na implantação do plano de ação; 4) as estratégias utilizadas; 5) os efeitos que já puderam ser sentidos; 6) as perspectivas referentes ao movimento pró-mudança. Tendo em vista o recorte deste artigo, serão abordados apenas os resultados referentes às categorias 3 e 4 .

O corpus da pesquisa se constituiu dos relatos de observação descritos no caderno de campo, das transcrições das entrevistas e dos TCCs. Os TCCs e as entrevistas foram analisados conjuntamente, ampliando os dados referentes à mudança e ao contexto locorregional. 
Os TCCs, relatos do caderno de campo e as entrevistas foram codificados como IESPu quando se tratava de entrevistadas que tinham vínculo com instituições de ensino superior públicas; como IESPr as vinculadas a instituições de ensino superior privadas; e como ISP as vinculadas ao serviço. As entrevistas foram numeradas em cada grupo conforme a ordem em que foram realizadas. Assim, a última entrevistada vinculada a uma instituição de ensino superior pública recebeu o código IESPu14.

Optou-se pela análise de conteúdo por meio da análise temática. Segundo Bardin ${ }^{11}$, esta técnica possibilita o estudo de motivações, atitudes, valores, crenças e tendências. Para Triviños $^{12}$, seu uso revela o que à primeira vista não se apresenta com a devida clareza. Os recortes por tema foram realizados por meio do programa $\operatorname{Logos}^{13}$.

O projeto de pesquisa deste estudo foi analisado e aprovado por meio do parecer no 260/06 do Comitê de Ética em Pesquisa Envolvendo Seres Humanos, da Universidade Estadual de Londrina (CEP/UEL), atendendo à Resolução MS/ CNS 196/96 ${ }^{14}$.

\section{RESULTADOS E DISCUSSÃO}

\section{Dificuldades vivenciadas na implantação das mudanças}

As dificuldades estruturais identificadas pelas entrevistadas durante a implantação dos processos de mudança apontaram uma inadequação da infraestrutura das instituições públicas e da rede de serviços. Em contrapartida, a infraestrutura das instituições privadas foi considerada adequada. Estes problemas também foram identificados por Bordenave e Pereira ${ }^{15}$, que, além de destacarem a falta de equipamentos, de salas de aula apropriadas e de acervo bibliográfico, afirmam que, quando o recurso existe, muitas vezes, é mal empregado, gerando efeitos limitados e próximos aos alcançados quando não se faz uso do recurso. As entrevistadas do serviço mencionaram que a falta de espaço para receber os estudantes na rede de serviços foi um importante limitador da articulação entre ensino e serviço. Entretanto, ressalvaram que as dificuldades estruturais, por mais limitantes que fossem, não eram impeditivas para a implantação da proposta de mudança.

Entre as dificuldades humanas/metodológicas, as participantes das instituições de ensino, públicas e privadas, ressaltaram dificuldades semelhantes. A dissociação do processo de ensino-aprendizagem em processo de ensino, foco do professor, e em processo de aprendizagem, foco dos estudantes foi citada como uma dificuldade para a ressignificação do papel do professor e do aluno. O processo visto de forma dissociada faz com que o professor se exima de suas responsabilidades com a aprendizagem e assuma apenas seus deveres com o ensino. O mesmo ocorre com o estudante, que se isenta de seus deveres no processo de ensino.
[...] eu percebo que os nossos professores trabalham como se o processo todo fosse centrado neles e não no aluno. Quando discutimos isso com eles, observamos uma grande resistência para mudar [...]. (IESPu07)

O ensinar e o aprender formam uma unidade que delimita, culturalmente, o campo de constituição do indivíduo. São processos indissociáveis em que o professor participa ativamente da constituição de processos psíquicos do estudante. $\mathrm{O}$ professor deve, portanto, se responsabilizar, em parceria com o estudante, pelo processo de aprendizagem. Vygotsky ${ }^{16}$ demonstra a unidade do processo ensino-aprendizagem em sua abordagem histórico-cultural e, neste processo, a cultura e o indivíduo se constituem mutuamente ${ }^{16,17}$.

Outra importante dificuldade mencionada foi o distanciamento entre o processo de ensino-aprendizagem e os processos de avaliação nas instituições de ensino. Para algumas participantes, esta situação foi entendida como desonesta e injusta. Para outras, a avaliação cognitiva foi citada como ainda necessária e tida como instrumento de estímulo à participação e ao compromisso do estudante.

O professor abre, faz uma metodologia ativa e depois faz uma avaliação tradicional. Não tem jogo mais sujo do que esse. Você falou uma coisa para o aluno, ele fez a parte dele e participou, mas é a prova que dá a nota. Isso é uma sabotagem danada. (IESPu09)

A gente trabalha um currículo totalmente inovador $\mathrm{e}$ chega ao final da disciplina e dá prova. E tem de dar prova mesmo, porque o aluno só tem medo é da prova. Eles só têm preocupação se cai ou não na prova. (IESPr01).

A avaliação da aprendizagem, muitas vezes, é praticada de forma independente do processo de ensino-aprendizagem. Com as mudanças neste processo, o distanciamento da avaliação ficou evidenciado, refletindo-se no distanciamento na relação professor-estudante. A avaliação que usamos hoje não é diferente das aplicações de exames realizadas há 400 anos nas escolas da Ordem Jesuítica ${ }^{18}$.

Para Peña ${ }^{19}$, a avaliação deve possuir duas funções: a) diagnóstica, que detecta as falhas de aprendizado que sinalizam ao professor uma revisão de seus procedimentos de ensino, visando atender às necessidades de aprendizagem; b) formativa, que possui características diagnósticas, porém analisa cada erro e não apenas soma erros e acertos. Nessa linha, aplica-se a avaliação contínua, que identifica a progressão prevista, sendo que a postura do professor é de investigar para reformular.

O papel da universidade, quando entendido como formatador de reproduções em uma linha de produção em série, 
também foi identificado como limitador para a apropriação da proposta de mudança pelos professores. Para as participantes, a mudança dos paradigmas hegemônicos deve preceder a busca pelo método. Os proponentes devem saber o que querem como resultado e por que querem essa mudança, para depois optar e se qualificar com o método que auxilie no processo de mudança.

Para uma entrevistada, a ideia da instituição como reprodutora era entendida como a real função da instituição de ensino:

O aluno chega de um jeito, mas a gente molda o aluno. Eu acho que a escola molda o aluno. Tem alunos que não, nem o sistema consegue mudar, porque é do caráter de cada um. [...] a gente pega na mão deles e leva até a porta, abre e diz para ele passar. (IESPr04)

Esta professora ressalta que o estudante deve ser conduzido pelos tortuosos caminhos de sua graduação, mas esquece que, assim que ele se torna profissional, esse ambiente controlado se evapora, e a realidade conflituosa se apresenta. O estímulo à reflexão, à crítica e à tomada de decisão ajudará este futuro profissional em suas decisões posteriores, tornando-o um cidadão e profissional consciente de seus direitos e deveres.

Para Arantes et al. ${ }^{20}$, o ato de ensinar não se dissocia do ato político de buscar produzir crítica sobre o instituído, visando à criação de linhas de fuga, não no sentido de fugir, mas no sentido de abrir novos caminhos que afirmem a cognição como subjetivação e vida.

A desvalorização das pessoas e dos relacionamentos em prol da proposta de mudança foi entendida como uma dificuldade decorrente principalmente do desrespeito ao tempo de apropriação da proposta de cada ator. O desgaste nas relações pessoais acaba por desencadear diversas outras dificuldades. Deve-se lembrar que não existe proposta de mudança sem o envolvimento das pessoas, seja ele positivo ou negativo. Cabe ao grupo propositor esclarecer os objetivos, aproximando a proposta dos anseios de mudança dos envolvidos.

O entendimento da importância das pessoas no processo de mudança acaba por decifrar a lentidão nos tempos de implementação da mudança - o tempo para a construção da proposta, o tempo para a apropriação dos envolvidos e o tempo para a implantação. Ressaltou-se que a ingenuidade de imaginar que o processo seria rápido provocou uma importante ansiedade que, mesmo sem intenção, se alastrou pelo departamento e entre os estudantes. A importância do tempo para apropriação do processo de mudança está evidenciada na fala a seguir:
[...] não entendemos que as coisas chegam para os indivíduos do grupo em tempos diferentes. Com alguns professores foi mais difícil de trabalhar do que com outros. Deveríamos ter respeitado esse tempo de absorção, mas sem nunca desistir. (IESPu04)

O respeito ao tempo de apropriação de cada ator é vital para o sucesso da proposta de mudança. Quando o processo é acelerado, não se respeitando essa interiorização, os envolvidos tendem a rejeitar a proposta sem ao menos compreendê-la. Assim, incrementa-se o número de opositores, e a proposta acaba por ser rejeitada pelo grupo.

A hiperespecialização dos professores pode dificultar esse trabalho coletivo. A especialização foi entendida como um processo que acaba por individualizar e restringir, dificultando a discussão integradora e generalizada, necessária à discussão em grupos heterogêneos. A hiperespecialização não é um problema por si só. O problema se apresenta quando o professor se isola em seu conhecimento e não o articula com os demais conhecimentos.

Outro ponto limitador do trabalho coletivo foi que os diferentes grupos, em muitos relatos, não assumiram as propostas como sendo do coletivo. O plano de mudança era entendido como a proposta do professor que participou do curso de ativadores. Esse descolamento, em alguns casos, abalou ainda mais as relações pessoais. "O que eu senti foi que era uma proposta minha e, mesmo que as pessoas concordassem, a condução acaba sendo de quem propõe." (IESPu13).

Essas dificuldades para o trabalho em grupo, associadas à baixa governabilidade do proponente, limitaram a profundidade de muitas propostas, além de provocarem a sensação de solidão e de impotência frente à realidade vivenciada. Esse sentimento pôde ser mais bem observado nas instituições que não dispunham de outros egressos do curso de ativação.

A falta de disponibilidade para a qualificação ou mesmo para a articulação com a proposta de mudança foi sentida por todas as entrevistadas. Uma das participantes relatou ter existido muita resistência por parte dos colegas em participar de oficinas de qualificação. Ela mencionou que os colegas não queriam discutir o problema e construir possíveis soluções. Ansiavam por uma "receita pronta", que resolvesse o problema identificado. Eles diziam: “A gente não quer mais oficina, a gente já aprendeu. O problema é que não dá para colocar em prática. A gente só quer saber como resolver esse problema." (IESPu03)

$\mathrm{O}$ grupo argumentava que conhecia a proposta de mudança, porém não conseguia implantá-la. O ruído na comunicação, resultado de relações interpessoais e profissionais desgastadas, dificultou a clareza da proposta e sua implantação. 
Também foi identificada uma baixa autoestima dos professores, provocada por baixos salários, inúmeras demandas e pouco apoio institucional. Associa-se a isto a desvalorização do ensino na graduação frente à pesquisa ou mesmo ao ensino na pós-graduação.

Para Gadotti ${ }^{21}$, somente quem faz pesquisa tem algo a ensinar, portanto todos os professores devem ser pesquisadores. A crítica e o avanço provêm da pesquisa, e os professores que não desenvolvem pesquisas são reprodutores de conhecimentos absorvidos de outros pesquisadores e estimularão apenas reproduções e nada avançará. Porém, o modo como se avaliam os programas de pós-graduação faz com que os professores dispensem boa parte de suas horas com a pesquisa e, cada vez mais, valorizem menos a graduação. É a publicação científica que faz o mundo docente universitário girar, e a graduação se traveste de entrave a esse movimento.

O balanço entre o professor que não pesquisa e o pesquisador que não gosta de ser professor provoca, cada vez mais, uma graduação abafada pela pós-graduação. Os estudantes da graduação deixam de ser ouvidos e não se aproximam das descobertas alcançadas na pós-graduação. Com isso, o egresso sai da universidade sem tomar conhecimento das necessidades da população identificadas pelos egressos da pós-graduação, que pouco aplicam as informações construídas em suas produções. A produção científica não pode ser o fim, mas o meio para atender às necessidades da população.

A dificuldade de se abrir ao novo, de experimentar o diferente foi colocada como uma barreira ao estímulo de outros professores durante a implantação da proposta de mudança. Cabe ressaltar que, em muitos casos, o novo acaba por retirar o professor de sua zona de conforto.

O desconforto é o motor da mudança e pode ser percebido de diversas formas, mas deve ser valorizado para se desdobrar em mudanças.

Aí você esbarra em todo o contexto desfavorável. Então você para de ficar desconfortável. Você para de ouvir. Você não dá mais oportunidade, não escuta. Desconforto é sofrimento, sofrimento é ruim, e coisa ruim eu não quero. Dou a minha aula, o sujeito assiste e tudo bem. (IESPu14)

Uma das entrevistadas destacou que, muitas vezes, falta humildade ao professor para assumir que ele não é o detentor de todos os saberes e que não tem todas as respostas. Para ela, o professor sofre muito com a implantação do processo porque, em grande parte dos casos, perde sua identidade durante o processo. Outra participante trouxe esses sentimen- tos em outra perspectiva: a sensação de estar "zerada" após a implantação do processo de mudança, a falsa ideia de que a mudança afastou tudo o que ela sabe. A mudança, em geral, desconstrói o professor, mas não o elimina. "Porque vamos mudar um pouco o método de ensinar parece que elas deixam de ser professoras. Parece que esqueceram tudo." (IESPu01).

Essas fragilidades são naturais dos seres humanos. A vontade de provar o novo é abafada pelo receio do desgosto. A desconstrução exigida para a mudança é supervalorizada e acaba por abalar as bases da reconstrução. A mudança gera receio, que gera um fechar-se em si, que acaba por gerar resistência ao processo como um todo. Este processo negativo se desenvolve quando as insatisfações pessoais que estimulariam a mudança ainda não são compreendidas e trabalhadas.

Essa visão, de tudo ou nada, também foi vivenciada durante a avaliação dos módulos acadêmicos ou interdisciplinares. Os módulos que funcionavam bem eram mantidos, enquanto os que não funcionavam assim tão bem eram descartados em sua totalidade, sem considerar os pontos positivos alcançados em sua reformulação.

Diversas dificuldades foram associadas à construção do vínculo entre professor e estudante. Destacam-se o descompromisso e a imaturidade do estudante em assumir seu papel no processo e, principalmente, a expectativa de receber os conhecimentos prontos.

Segundo Ramos-Cerqueira ${ }^{22}$, a relação professor-estudante é uma relação entre desiguais. Em muitos casos, possuir o saber e o conhecimento fornece poder ao professor e desqualifica aquele que não o possui, acarretando passividade e atitude acrítica quanto ao processo de aprendizagem. Esse vínculo de dependência, muitas vezes de submissão, perde força com as metodologias ativas de aprendizagem. Porém, é a postura do professor e do estudante que precisa ser modificada para estabelecer o vínculo de parceria, benéfico para ambos.

Assim como o professor tem dificuldade de desempenhar esse novo papel, o estudante também deve ser contextualizado nesse processo ${ }^{23}$. A crítica e a reflexão sobre verdades tidas anteriormente como absolutas são um processo difícil e muitas vezes doloroso. Ressignificar essas verdades torna-se um desafio tanto para o estudante quanto para o professor.

A falta de tempo, ou mesmo de espaços, para discutir as questões referentes aos processos de mudança foi identificada como resultado da sobrecarga administrativa vivenciada nos departamentos. Os encontros existentes eram ocupados por questões administrativas, e a pouca disponibilidade dos professores para reuniões extras fez com que a proposta não se convertesse em uma proposta do grupo. "A gente discute 
todas as questões administrativas, acadêmicas e de projetos em uma reunião de departamento, uma hora, uma vez por mês." (IESPr01).

Ressaltou-se a desvalorização dos profissionais do serviço que atuam como preceptores. Esse profissional foi entendido, muitas vezes, como pouco qualificado para a preceptoria, entretanto é sempre esquecido nas oficinas de qualificação promovidas pelas instituições de ensino. A inserção dos estudantes é entendida como mais uma demanda para o serviço, que não está preparado para suprir as necessidades deles. "Nós, no serviço, não estamos preparados para receber os alunos. Nem nós e nem o próprio serviço. Ajeitar o lugar até que é mais simples. O problema é 'ajeitar' o preceptor." (ISP03).

A descontinuidade das políticas públicas, em alguns casos decorrente da mudança nos cargos mais elevados de comando, também foi entendida como um limitador para a implantação de processos de mudança, em especial para a articulação ensino-serviço. Mesmo a política AprenderSUS sofreu fortes impactos com as mudanças ocorridas em 2005 no MS. Graças a esforços de muitos e à articulação de outros, o curso foi realizado, e a política de Educação Permanente em Saúde está em desenvolvimento.

Dificuldades financeiras para a implantação da proposta emergiram nos discursos com diferentes aproximações. As entrevistadas entendem que as metodologias ativas acrescentam um ônus à instituição e que sem apoio financeiro do MS e do MEC será impossível uma mudança profunda e sustentável.

Pôde-se observar que muitas das dificuldades aqui trabalhadas foram semelhantes às que motivaram a organização do curso de ativadores e, portanto, já eram esperadas. A grande questão é como essas participantes as contornaram.

\section{Estratégias empregadas na implantação das mudanças}

As estratégias são as ferramentas que aproximam o planejado e a realidade. Cada contexto pede estratégias específicas, que, quando mal usadas, acabam por afastar as pessoas envolvidas e, com isso, os objetivos da realidade.

Entre as estratégias metodológicas, várias entrevistadas relataram que conseguiram divulgar os conhecimentos apreendidos no curso de especialização. Com isso, ativaram novos atores e ampliaram os espaços para discussão da mudança. A disponibilidade e a percepção para adaptar o plano de mudança pensado à realidade que se apresentava no momento da implantação foram consideradas importantes para o sucesso da proposta, assim como foi essencial aguardar o momento certo para lançar as estratégias.

As participantes mencionaram o uso de algumas estratégias metodológicas centradas no trabalho em sala de aula, especialmente na interação com os estudantes. Entre elas, a apresentação do Projeto Político-Pedagógico do curso aos estudantes com o objetivo de demonstrar a ligação entre as disciplinas e suas relações com o perfil do egresso requerido. Outras professoras começaram a organizar os estudantes em roda durante as aulas e a trabalhar com textos, revistas e artigos com vistas a se aproximar da realidade e articular os conhecimentos trabalhados.

$\mathrm{O}$ trabalho com materiais que aproximam assunto estudado e realidade tende a estimular a participação dos estudantes, facilitando o desenvolvimento do vínculo professor-estudante. Deve-se considerar que a participação ativa dos estudantes foi cerceada durante muitos anos e que estes também devem se adaptar ao novo processo. O estímulo deve ser constante e persistente para que o estudante perceba os resultados positivos de sua participação.

Também foi mencionado que o trabalho com as avaliações após correção se mostrou eficiente na assimilação dos erros cometidos pelos estudantes e na sistematização final dos assuntos trabalhados. Outra professora identificou este mesmo problema e passou a construir com os estudantes a sistematização dos conteúdos trabalhados ao final de cada aula, sendo o conteúdo resgatado no início da aula seguinte por meio de uma situação-problema baseada em algum acontecimento real.

Apresentar o significado de cada ação facilitou a ancoragem do novo conhecimento com saberes assimilados anteriormente. O uso desta estratégia facilitou o processo de ensinoaprendizagem dos estudantes, que se tornaram mais compromissados e questionadores. Estudantes e professores atuam durante o processo de ensino-aprendizagem promovendo a ressignificação dos conhecimentos prévios e a desconstrução de verdades tidas como absolutas com a posterior reconstrução de novas verdades. Esse processo deve ser sempre estimulado e valorizado, observando e trabalhando as angústias dos estudantes.

Com referência às estratégias humanas/administrativas, algumas entrevistadas relataram que conseguiram melhores resultados após a inserção do tema da mudança nos espaços coletivos de discussão. Num dos casos, essa estratégia resultou na criação de uma comissão de professores ligados ao departamento para discutir e desenvolver as ações pró-mudança.

$\mathrm{O}$ apoio de assessores externos ajudou na condução do processo de mudança em algumas instituições. As próprias entrevistadas destacaram que o assessor vinha com uma perspectiva de apoiar e nortear os esforços dos professores locais, o que era fundamental nos espaços onde as falas dos atores locais eram pouco valorizadas. "Foi importante ter uma pessoa com experiência e de fora da instituição para nos ajudar a fo- 
car nossas ações. [...] nós conduzíamos o processo, ela ajudava com sua experiência." (IESPu04).

O envolvimento de funcionários nos processos de ensino-aprendizagem potencializou a proposta de uma das participantes. A valorização dos profissionais que recebiam os estudantes na rede de serviços facilitou a inserção dos estudantes e a aprendizagem deles. Com o vínculo ensino-serviço estabelecido, as trocas e o crescimento de ambos os cenários podem se concretizar. A valorização dos preceptores foi tida como fundamental para a qualificação da inserção dos estudantes nos serviços de saúde.

Criar grupos de estudos multiprofissionais com apoio de pedagogos e com livre demanda também foi uma das estratégias usadas para a reflexão e qualificação da prática docente. Este grupo focava o processo de trabalho do professor e discutia as principais demandas trazidas pelos próprios participantes. "O trabalho com os professores de vários cursos focava-se na própria necessidade deles. Com isso, eles se mostravam motivados e se aproximavam como um grupo." (IESPu12).

Espaços de qualificação docente são essenciais, visto que, em muitos casos, o profissional não trabalha as questões pertinentes à pedagogia ou à andragogia durante sua formação. Frequentemente, o professor é selecionado pelo trabalho desenvolvido em pesquisas com publicações científicas e não pela capacidade de ensinar ${ }^{24,25}$. A limitada qualificação para as questões de ensino-aprendizagem promove a reprodução de modelos considerados válidos, observados anteriormente, e sua experiência prática cotidiana $^{26}$. Em geral, os professores assumem ideias, atitudes e comportamentos da formação vivenciada durante o período em que eram estudantes sem a devida reflexão ${ }^{27}$.

Segundo Benedito et al. ${ }^{28}$, a formação proporcionada apenas pelas experiências anteriores é insuficiente, mesmo considerando a capacidade autodidata do professor. Portanto, a formação permanente do professor é imprescindível à evolução do ensino em saúde. Este fato é reconhecido, porém, em muitos casos, com poucas ações das instituições, que ainda optam por metodologias tradicionais - fato não muito distante das instituições que usam novas metodologias de ensino-aprendizagem ${ }^{29}$.

Uma das entrevistadas revelou a importância do resgate dos objetivos almejados e da valorização dos avanços conquistados. Com isso, segundo ela, todos os envolvidos sabiam o porquê de suas ações e se motivavam com os avanços.

É importante que todos saibam das metas para que sejam ativos e não apenas robôs dentro do processo. Absorver os avanços também é fundamental para que não se percam frente às barreiras. (IESPu09)
Algumas participantes destacaram a organização do trabalho por projetos, envolvendo, com isso, mais professores e disciplinas. O trabalho por projetos inicialmente foi desenvolvido com a articulação das propostas de mudança que já estavam em desenvolvimento nos departamentos. Posteriormente, essas propostas foram articuladas com os projetos de pesquisa e de ensino existentes no departamento.

Projetos de aprendizagem buscam estimular a criatividade e a aproximação entre os objetos de estudo e os sujeitos envolvidos. Essa aproximação motiva e estimula o envolvimento dos estudantes, tornando o processo ativo, criativo e crítico. $\mathrm{O}$ trabalho por projetos de aprendizagem pode existir concomitantemente a grades curriculares convencionais. Entretanto, em geral, mesmo com a sobreposição, os envolvidos acabam valorizando o cumprimento da grade curricular, esquecendo-se dos projetos de aprendizagem.

O trabalho por projetos também serviu como estratégia na busca de parceiros com maior governabilidade, dando mais força de ação à proposta. Uma das entrevistadas relatou que, ao invés de firmar parcerias, sua estratégia foi ocupar cargos de gestão que ampliassem sua governabilidade.

Ambas as estratégias apresentaram dificuldades durante sua implementação. Com parceiros a proposta pode se tornar mais coletiva, mas o comprometimento destes parceiros com a mudança deve ser reavaliado em todos os momentos. A busca por cargos de gestão em níveis mais elevados se mostrou desgastante não só para o ativador, mas também para a própria proposta de mudança.

Uma das entrevistadas optou por construir o plano de mudança com um pequeno grupo de pessoas. Para ela, a mudança pode ser mais significativa quando parte de um pequeno grupo contagia o coletivo. A construção coletiva, com humildade para ouvir e aprender, também foi relatada por outras participantes. $\mathrm{O}$ respeito às dificuldades e a tolerância com o tempo de apropriação de cada envolvido foram tidos como essenciais no processo. Para Gramsci apud Macciocchi ${ }^{30}$, só podemos ser intransigentes na ação se tivermos sido tolerantes na discussão. Destacou-se que as fragilidades apresentadas pelos sujeitos mais resistentes à proposta devem ser trabalhadas e apoiadas.

Não se pode perder ninguém pelo caminho. Cada um que fica para trás deve ser apoiado para acompanhar o grupo. No início você imagina que um resistente não terá força para barrar o processo, mas você se assustaria com o estrago que ele pode fazer. (IESPu08)

A mudança que nasce da necessidade dos envolvidos é mais forte e representativa que a mudança que nasce de pou- 
cos "iluminados". A motivação deve ser estimulada em cada um para que todos se percebam insatisfeitos e com necessidade de mudança. Esse processo facilita a implementação e a proatividade, já que a proposta passa a ser entendida como uma proposta do grupo e não de apenas uma pessoa.

Com isso em mente, algumas participantes relataram a necessidade de implantar progressivamente propostas mais transformadoras que tenham como foco a valorização do bem-estar coletivo e as relações interpessoais. "A proposta não pode ser mais valorizada que as pessoas. Afinal, são as pessoas que desenvolvem a proposta, sem elas não haveria razão de ser." (IESPu09).

A busca por financiamento em fontes diversas foi possibilitada pela reestruturação da proposta de mudança como projeto de ensino, extensão ou pesquisa. Entretanto, mesmo com esta estratégia, poucas propostas de mudança contavam com apoio financeiro durante a realização desta pesquisa.

\section{CONSIDERAÇÕES FINAIS}

O curso de ativação de processos de mudança proporcionou uma grande proliferação de propostas de mudança na formação em espaços locorregionais. Este era um dos objetivos pretendidos com a estruturação dos TCCs em planos de ação de mudança. Entretanto, pela limitada articulação e falta de governabilidade, as mudanças se caracterizaram, em geral, como superficiais e restritas. Porém, mesmo limitadas, constituíram experiências fundamentais para que mudanças mais profundas possam ocorrer.

Identificou-se que dificuldades estruturais são limitadoras, mas, na maioria dos casos, não impedem a implantação de mudanças. Destacou-se como uma grande barreira para a mudança na formação superior em saúde a falta de disponibilidade, de compromisso e de qualificação de parte dos docentes. As estratégias mais interessantes observadas foram aquelas referentes às relações pessoais, que compreendem e respeitam os tempos e as limitações dos envolvidos, garantindo apoio metodológico e pessoal. A articulação de parcerias e a reflexão docente individual e coletiva foram essenciais para as mudanças observadas como mais consistentes e duradouras.

A realidade demonstra que os profissionais fragmentam suas ações na tentativa de encaixar a realidade que se apresenta no conhecimento fragmentado construído durante sua formação ${ }^{7}$. A realidade complexa e integral deve inundar os processos de ensino-aprendizagem, propiciando profissionais mais críticos, reflexivos e com práticas integrativas e éticas. $\mathrm{O}$ trabalho em equipe multiprofissional deve ser estimulado e priorizado sempre que possível. Estas são estratégias fundamentais para estimular a mudança na formação e, por conseguinte, a mudança na prática em saúde.
A união entre ensino (professores e estudantes), serviço e comunidade se torna vital para nortear os processos mais profundos de mudança na formação. São fundamentais para efetivar a mudança de paradigma na educação e atenção à saúde, iniciativas do Movimento de Reforma Sanitária e políticas públicas de incentivo que visem qualificar estes processos e não apenas financiá-los.

\section{REFERÊNCIAS}

1. Ministério da Saúde. Secretaria de Gestão do Trabalho e da Educação em Saúde. Departamento de Gestão da Educação na Saúde. AprenderSUS: o SUS e os cursos de graduação da área da saúde. Brasília: MS; 2004.

2. Feuerwerker LCM, Lima VV. Formação de ativadores de processos de mudança: uma estratégia do AprenderSUS. Olho Mágico. 2004;11(4):15-8.

3. Fundação Oswaldo Cruz. Educação à Distância. Curso de Ativação de Processo de Mudança na Formação Superior de Profissionais de Saúde. Caderno do especializando. Rio de Janeiro: Fiocruz; 2005.

4. Brasil. Ministério da Educação. Conselho Nacional de Educação. Resolução CNE/CES nº 4, de 07 de novembro de 2001. Institui Diretrizes Curriculares Nacionais do Curso de Graduação em Medicina. Diário Oficial da União. Brasília, 9 nov. 2001; Seção 1, p.38.

5. Brasil. Ministério da Saúde. Ministério da Educação. Programa nacional de reorientação da formação profissional em saúde PRÓ-SAÚDE. Brasília: MS; 2005.

6. Mattos RA. Os Sentidos da Integralidade: algumas reflexões acerca de valores que merecem ser defendidos. In: Pinheiro R, Mattos RA, orgs. Os Sentidos da Integralidade na atenção e no cuidado à saúde. Rio de Janeiro: UERJ; 2001. p. 39-64

7. González AD, Almeida MJ. Integralidade da Saúde: norteando mudanças na graduação dos novos profissionais. Ciênc Saude Coletiva [periódico na internet] no prelo 2007. [acesso em 22 fev. 2008]. Disponível em: http://www. abrasco.org.br/cienciaesaudecoletiva/artigos/artigo_int. php?id_artigo $=665$

8. Brasil. Ministério da Saúde. Ministério da Educação. Organização Panamericana da Saúde. Promed: Programa de Incentivo a Mudanças Curriculares nos Cursos de Medicina. Brasília: Secretaria de Políticas da Saúde; 2002.

9. Almeida MJ. Educação médica e saúde: possibilidades de mudança. Londrina: Ed. UEL; Rio de Janeiro: ABEM; 1999.

10. Costa NMSC. Docência no ensino médico: por que é tão difícil mudar? Rev Bras Educ Med. 2007;31(1):21-30. 
11. Bardin L. Análise de conteúdo. Lisboa: Edições 70; 1979.

12. Triviños ANS. Introdução à pesquisa em ciências sociais: a pesquisa qualitativa em educação. São Paulo: Atlas; 1987.

13. Camargo Junior KR. Apresentando LOGOS: Um gerenciador de dados textuais. Cad Saude Publica. 2000;16(1):286-7.

14. Brasil. Ministério da Saúde. Conselho Nacional de Saúde. Resolução no 196/96, de 10 de outubro de 1996. Aprova as diretrizes e normas regulamentadoras de pesquisas envolvendo seres humanos. Brasília; 1996.

15. Bordenave JD, Pereira AM. Estratégias de ensino-aprendizagem. 27ํㅡㄹ ed. Petrópolis: Vozes; 2006.

16. Vygotsky LS. A formação social da mente. São Paulo: Martins Fontes; 1984.

17. Vygotsky LS, Luria AR, Leontiev AN. Linguagem, desenvolvimento e aprendizagem. São Paulo: Ícone; 1988.

18. Luckesi CC. Avaliação da aprendizagem escolar. $12^{\underline{a}}$ ed. São Paulo: Cortez; 2002.

19. Peña MDJ. A avaliação na sala de aula: da prática da avaliação tradicional à avaliação formativa. In: PEC: Formação Universitária.. São Paulo: [s.n.]; 2002; Módulo 2, Tema 2.

20. Arantes EMM, Lobo LF, Fonseca TMG. Pensar: a que será que se destina? Diferentes tempos de uma reflexão sobre a morte anunciada do educador. Psicol Soc. 2004;16(1):50-68.

21. Gadotti M. Educação e Poder: introdução à Pedagogia do Conflito. 14 $14^{\mathrm{a}}$ ed. São Paulo: Cortez; 2005.

22. Ramos-Cerqueira ATA. A prática pedagógica como processo de comunicação: a relação professor-aluno como eixo: o ponto de vista psicológico. Interface Comun.Saúde Educ. 1997; 1(1):187-91.

23. Zabala A. A prática educativa: como ensinar. Porto Alegre: Artmed; 1998.

24. McLeod PJ, Steinert Y, Meagher T, McLeod A. The ABCs of pedagogy for clinical teachers. Med Educ. 2003;37(7):638-44.

25. Mclean M. Reawarding teaching excellence. Can we measure teaching "excellence"? Who should be the judge? Med Teach. 2001; 23(1):6-11.
26. Finucane P, Rolfe I. Graduates' verdict on medical teachers: the minority who teach do it well. Med Teach. 1996;18(1):57-9.

27. Mizukami MGN. Teoria, prática e reflexão na formação do profissional em educação. Inter-ação (Goiana). 1997;21:39-60.

28. Benedito AV, Ferrer CV, Ferreres PV. La formación universitária a debate: análisis de problemas y planteamiento de propuestas para la docencia y la formación del profesorado universitario. Barcelona: Universidad de Barcelona; 1995.

29. Venturelli J, Fiorini V. Programas educacionais inovadores em escolas médicas: capacitação docente. Rev Bras Educ Med. 2001;25(1):7-21.

30. Macciocchi Maria-Antonieta. A favor de Gramsci. $2^{\underline{a}}$ ed. Rio de Janeiro: Paz e Terra; 1980.

Apoio: Financiamento do Conselho Nacional de Desenvolvimento Científico e Tecnológico (CNPq) por meio do processo 408938/2006-4.

\section{CONTRIBUIÇÃO DOS AUTORES}

Alberto Durán González e Márcio José de Almeida participaram de todas as fases de construção do artigo.

\section{CONFLITO DE INTERESSES}

Declarou não haver.

\section{ENDEREÇO PARA CORRESPONDÊNCIA}

Alberto Durán González

Rua Alagoas, 995 - apt ${ }^{\mathrm{o}} 704$

Centro - Londrina

CEP 86010-520 - PR

E-mail: betoduran_fbq@yahoo.com.br 